\title{
Fairness and voting
}

\section{Volker Hahn}

Published online: 6 April 2007

(c) Springer-Verlag 2007

\section{Erratum to: Soc Choice Welfare DOI: 10.1007/s00355-006-0177-0}

In this erratum I would like to clarify one of the broad conclusions in Hahn (2007). Without inequity aversion, the median voter is always indifferent between the candidates at the beginning of the second period. Thus for the median voter infinitely many voting behaviors and, in particular, all retrospective voting rules are time-consistent. Introducing fairness implies a unique retrospective voting rule under the mild assumption that non-pivotal voters always vote for the party they would choose if they were pivotal. Moreover, retrospective voting would exist even if the median voter were not indifferent with respect to both parties' bliss points. In Hahn (2007) the contribution with regard to the foundation of retrospective voting has been presented in an incorrect way.

The online version of the original article can be found at http://dx.doi.org/10.1007/s00355-006-0177-0.

V. Hahn (凶)

CER-ETH - Center of Economic Research, ETH Zurich, ZUE D 13, Zürichbergstrasse 18, 8032 Zurich, Switzerland e-mail: hahn@mip.mtec.ethz.ch 